\title{
Old or Age Indeterminate Anterior Myocardial Infarction by ECG Finding
}

National Cancer Institute

\section{Source}

National Cancer Institute. Old or Age Indeterminate Anterior Myocardial Infarction by

ECG Finding. NCl Thesaurus. Code C102684.

An electrocardiographic finding of pathologic Q waves in leads V3 and V4, which is suggestive of myocardial infarction of the anterior wall of the left ventricle, without evidence of current or ongoing acute infarction. (CDISC) 